\title{
DISCIPLINES AT PARALLEL PLAY
}

\author{
Linda K. Acitelli
}

The University of Michigan

\begin{abstract}
Comparing relationship researchers to children engaging in parallel play, the author questions the popular impression that the field of personal relationships is interdisciplinary. The term 'interdisciplinary' is contrasted with 'multidisciplinary'. Being interdisciplinary requires researchers to integrate different perspectives on the same problem from more than one discipline. Being multidisciplinary requires only that researchers representing different disciplines be brought together and work on separate problems relevant to their own disciplines. Scanning a sample of the relationship literature, the author concludes that the field is more multidisciplinary than interdisciplinary. It is a field that approaches similar problems from different perspectives, but rarely integrates disparate work into a cohesive whole. With concrete suggestions, the author encourages relationship researchers from different disciplines to foster closer working relationships with one another in order to integrate their perspectives.
\end{abstract}

KEY WORDS $\bullet$ interdisciplinarity $\bullet$ multidisciplinarity $\bullet$ personal relationships

Working in a relatively young field, personal relationships researchers can be compared to children at parallel play - playing on the same playground, sometimes using the same or identical toys, having similar goals and remaining otherwise unaffected by each other (Parten, 1932; Salsinger, 1994). Researchers in this field have similar goals in the sense that we want to know more about personal relationships, but many of us never step outside of our own disciplines to get a different perspective from the one we have been 'trained' to have. Even though the field of personal relationships is generally assumed to be interdisciplinary, our field is actually multidisciplinary instead (L.A. Baxter, personal communication). The goal of this paper is to explore the role of interdisciplinarity in the field of personal relationships and to raise several questions: what does it mean to be interdisciplinary? Are we interdisciplinary or multidisciplinary? Should we become an interdisciplinary field? Why should

Address correspondence to Linda K. Acitelli, who is now at the Department of Psychology, University of Texas, Houston, TX 77204-5341, USA. [email: acitelli@uh.edu]

Journal of Social and Personal Relationships (C) 1995 SAGE (London, Thousand Oaks, cA and New Delhi), Vol. 12(4): 589-596. 
we care? What can we do to become interdisciplinary? Should we be content to remain multidisciplinary (thus continue to engage in parallel play)?

What does 'interdisciplinary' mean? Scholars argue about the meaning of 'interdisciplinary' and what it requires. Although there are several terms ending with the suffix 'disciplinary' (cross-, inter-, multi-, pluri-, trans-; see Epton et al., 1983, and Mayville, 1978 for reviews), the most useful distinction to be made is that between 'interdisciplinary' and 'multidisciplinary' (Lattuca, 1994). The distinction between 'multidisciplinary' and 'interdisciplinary' hinges on the degree of disciplinary integration. Multidisciplinarity is the juxtaposition of disciplines and is additive, not integrative (Klein, 1990). It requires only that researchers representing different disciplines be brought together and work on separate problems relevant to their own disciplines. Being interdisciplinary involves more integration of disciplinary perspectives than being multidisciplinary does. The extent of the integration, however, is open to debate. Some believe that exchanging ideas between disciplines is enough. Thus, citing papers from other disciplines would be evidence of interdisciplinarity. Others require that collaboration from the ground up is necessary (e.g. co-authors from different disciplines on the same project) and that researchers integrate different perspectives on the same problem from more than one discipline (e.g. Birnbaum, 1981).

For argument's sake, I embrace the latter, more extreme position. Our efforts, while presented side by side at conferences, in book chapters and in this journal, are not often integrated into a cohesive whole by a team of researchers from different disciplines. Thus, our field is more multidisciplinary than interdisciplinary. While interdisciplinarity does not necessitate integrating the entire field into a cohesive whole, it does require the integration of specific problems that are addressed by different disciplines. Do researchers in our field accomplish this sort of integration? I have the impression that, for the most part, we do not. How can we find out if this impression is realistic? One way is by examining articles in the relationship journals.

Is our field interdisciplinary or multidisciplinary? I examined a sample of 50 of the most recent articles from two relationship journals. Of those that were authored jointly and where the disciplines of all authors could be determined (36 articles), only $5(14 \%)$ were written by authors from more than one discipline. Admittedly, the sample size is small, and a more comprehensive study is recommended. However, my impression is that these data are representative, and most relationship researchers do not work with others outside of their own disciplines. (Family studies and communication departments may be special cases in which interdisciplinary work is already occurring due to the fact that their faculty members may have degrees from several disciplines. However, because the authors are identified as being affiliated within a particular family studies or communication department, one cannot tell from which discipline they received their degrees.) On the whole, the field of personal relationships field is not interdisciplinary.

The criterion of having authors from more than one discipline on a single article is a crucial defining characteristic, but it is not the only way to determine how much the various disciplines influence one another. Single-authored articles might be considered interdisciplinary as well. If articles within one discipline cite works from other disciplines, then this would provide some indication of contact between the various disciplines within the field of personal relationships. Good \& Still (1992: 565), when evaluating a similar 
situation regarding the interdisciplinarity of social psychology, stated that 'sociological social psychologists tend to cite studies in psychological social psychology but the reverse is not true'. This statement suggests a hypothesis for the personal relationships field. I surmised that the same kind of relationship exists between the two largest disciplines in our field, psychology and communication. My hypothesis was that, like the two social psychologies, most of the traffic would also be one-way. That is, communication researchers would cite psychologists more often than psychologists cite communication researchers.

I examined the reference lists of these same 50 articles discussed above. Of the 22 psychology articles, $3(14 \%)$ cited communication research. (Most of psychology's outside citations were in sociology, an ironic finding given Good \& Still's analysis.) Of the 15 communication articles, $13(87 \%)$ cited psychology research. Thus, given the sample of articles examined, my hypothesis was supported. There were only 4 articles out of 50 that did not cite journals from disciplines other than the one associated with the first author. All four of these articles were in psychology. Thus, 92 percent of the articles sampled cited work outside of their own discipline. These observations suggest that our disciplines are not completely separate in the sense that the overwhelming majority of articles in our field do cite work from more than one discipline. However, the field is not truly interdisciplinary because our journals have very few single papers co-authored by researchers from different disciplines.

On the other hand, there is plenty of evidence for multidisciplinarity in our field. Quite a few disciplines were represented in each issue (five in all, education, communication, family studies, sociology and psychology) not counting the different subspecialties within each field (e.g. social, developmental and clinical psychology). Although by no means definitive, my first attempt to determine whether the personal relationships field was multidisciplinary or interdisciplinary has landed squarely on the side of multidisciplinarity.

One might argue that the disciplines are not completely separate because we often tackle the same problems (research questions, issues, topics). Though many of us work on problems relevant to our own disciplines, there are several relationship researchers from different disciplines who work on the same problems from different perspectives. In a commentary in the ISSPR Bulletin (1994, Vol. 11, No. 1), Kelley presented his answer to the question 'What is a relationship?' (see also Kelley et al., 1983). He proposed a definition to help integrate the different disciplines by inviting us to achieve consensus about the 'major features of interaction states'. Furthermore, in an issue of INPR's Personal Relationship Issues (1992, Vol. 1, No. 2), three papers by authors (E. Rogers; Aron \& Aron; C. Berger) from two different disciplines also responded to the same question. I applaud the writers' efforts in tackling such important fundamental questions. I also welcome the opportunity to see how the same question can be answered in different ways. But these answers remain in juxtaposition to one another without some attempt to integrate them. Interestingly, we all carry some sort of model of what a relationship is, but what is it that we really know? We know that the answer varies from discipline to discipline and from person to person within disciplines. Thus our field is one in which the researchers work on similar problems from different disciplines, but they do not integrate their work into a cohesive whole even when the opportunity presents itself. Our field projects the illusion of being interdisciplinary, but even the illusion crumbles under close scrutiny. 
Why should we care? Why is it so important that we aim to loosen disciplinary boundaries? If it is correct to assume that interdisciplinary work often leads to creativity, then rigid disciplinary boundaries inhibit creativity (Diamond, 1992). Major advances in any field are often creative and often do not fit into any established discipline, yet can be recognized across disciplines. Often such an advance is eventually embraced by two or more disciplines because it makes sense from disparate observations. For example, Freud was a neurologist and a physician who eventually had tremendous influence in the literary world, psychology and other disciplines. Perhaps an example from well outside the domain of personal relationships will help clarify the value of crossing disciplinary boundaries. In the late 1960s, Mitchell developed a new theory regarding the primary means by which energy is generated in cells (the chemiosmotic theory of oxidative phosphorylation in mitochondria and chloroplasts, e.g. Mitchell \& Moyle, 1967). The generation of energy in cells is a fundamental issue that was originally approached as strictly a biochemical problem. Mitchell proposed, correctly, that energy was generated and stored as gradients of ions across the membranes of these bodies. Ion gradients were considered to be 'exclusively' the province of physiology. The melding of these two disciplines (biochemistry and physiology) was highly controversial then, but is routine now.

What can we learn from this example that is helpful to the field of personal relationships? Think of the problem of how energy is generated in cells as parallel to the problem of how relationships are defined. Some scholars are positing that talk creates relationships (see Duck, 1994, and this volume). As ion gradients were seen by biochemists as strictly a physiological problem, talk has been seen by psychologists as largely the province of communication scholars. Admittedly, talk has been discussed in the work of psychologists (e.g. conflict resolution, problem-solving, self-disclosure, social support), but more as a means to an end rather than as a creative force and focus of study in its own right. While some psychologists are beginning to see talk as a creative force in the generation of relationships (e.g. Acitelli, 1988, 1993; Genero et al., 1992; Duck, 1994), they have only just begun to empirically explore the creative nature of talk and its implications for relationships.

Should we become interdisciplinary? The idea that the personal relationships field should be interdisciplinary is not new. The editorial statement in the first issue of JSPR (Duck et al., 1984: 1) proclaimed the journal's interdisciplinary aims, stating it would "publish work on all aspects of social and personal relationships by workers from any discipline' and that a 'report should inform and be of use to workers in one or more of the constituent disciplines' (1984: 8 ). While these aims have been met, for the most part, they do not encourage true interdisciplinary research. That is, within these aims, scholars can keep writing in their own disciplines without ever incorporating ideas, theories or methods from any other discipline. Indeed, in another editorial statement from a more recent issue, Duck writes, 'Our eventual task as researchers is not to argue for this or that style of data gathering, but to compile a sensible composite picture from the jigsaw pieces that different research strategies ultimately create' (Duck, 1990: 11). This task is a laudable and realistic goal given the state of our field today.

However, I challenge the field to go beyond compiling sensible composite pictures from jigsaw pieces. Instead of creating separate jigsaw pieces, and then putting the pieces together into a composite picture, researchers might 
gain from talking to one another before the pieces are ever constructed and confer about their methods of data collection before collection begins. Perhaps several methods could be used to study the same phenomenon. New methods could emerge from such talk. We could take a pragmatic rather than a discipline-oriented approach to research on personal relationships (although, admittedly, disciplinary leanings are apparent from the types of things we choose to study and the ways we choose to study them). We could ask ourselves what kinds of data do we need to answer the research question and what are the best ways to gather them, instead of total immersion in a disciplinary worldview. For example, the study of narratives by Veroff (a psychologist) and colleagues (e.g. Veroff et al., 1993) has been recognized and valued across disciplines (psychology, family studies, social work and sociology to name a few). They have adopted several methods for analyzing the content and process of couples telling their stories and are not strictly tied to one disciplinary approach.

Philip Birnbaum has analyzed data from a stratified sample of 84 interdisciplinary research projects, ranging from solid state catalysts, fusion power and space exploration, to epilepsy, social indicators and the electrical properties of bone (see Klein, 1990), and has himself conducted several studies on the practice of interdisciplinary research. His findings indicate that

... interdisciplinary research is most useful during the initiating and implementing stages when comprehensiveness is important in identifying the problem, gathering the data, and analyzing the data. Interdisciplinary research activity is much less useful when conclusions are being drawn ... (Birnbaum, 1981: 9)

What can we do to become interdisciplinary? There are several ways in which interdisciplinary activity can be encouraged. Perhaps the single most powerful way to ensure that interdisciplinary work is supported is to obtain a grant for an interdisciplinary project. National funding agencies encourage projects that contain a variety of methods and have a broad range of potential applications. Utilizing a resource closer to home, a relationship journal could decide to have one special interdisciplinary issue every few years, where papers would be accepted only if co-authors of single articles were from different disciplines or if a single author could demonstrate (via references, methods and/or theories) that the ideas were not strictly the domain of one discipline. The authors could then be encouraged to make concluding comments, reflecting on the process of their collaboration and/or synthesis. For conferences, symposia could be planned that have the same requirement, not just that each presenter is from a different discipline, but that each paper contains ideas/methods from more than one discipline. Or a symposium could be planned around an entire project that has been created by researchers from several disciplines. If more of us engaged in interdisciplinary work, perhaps in several years one of our conferences could have as its theme 'Multiple Perspectives on Personal Relationships', encouraging, but not limiting itself to, work that integrates perspectives from different disciplines. (With this theme, several substantive topics could also be approached within disciplinary boundaries as well, so disciplinary researchers would not be excluded.)

Becoming interdisciplinary is not an easy task, and some might say impossible (e.g. Fish, 1994). According to Fish (1994), a field cannot be interdisciplinary. He believes that becoming interdisciplinary means that a field is in the 
process of becoming a new discipline with its own new boundaries, creating 'new lines and new authorities' (1994: 237). On the contrary, being interdisciplinary does not have to mean becoming a new discipline. In fact, we should be selective about which problems are appropriate for interdisciplinary work.

Indeed, Birnbaum does not support the idea of using interdisciplinary research for all research problems: 'Tightly integrated efforts need to be used selectively. Loosely coupled multidisciplinary efforts, as opposed to interdisciplinary efforts, may be more appropriate for the majority of research problems' (1981: 9). We should identify those problems for which an interdisciplinary approach is useful (see Birnbaum, 1981, for a discussion of the types of research problems that are best approached via interdisciplinary means). Just as we can form relationships with one another without losing our own identities, researchers from different disciplines can collaborate on interdisciplinary research without abandoning their own disciplines. The field of personal relationships can be conceived as a field within which interdisciplinary research is encouraged. It need not become a new discipline to do so.

In addition, we can apply what we have learned from relationship research to the relationships between researchers. As researchers of different disciplines, we need to develop an awareness of the relationships (Acitelli, 1993) between ourselves. We must have some stake in our relationships with each other if we wish to collaborate. Different disciplines have different perspectives, different orientations or world views, if you will, and there is bound to be conflict. Collaborative research requires that the researchers be committed to the research that can emerge from that relationship and thus to the relationship itself. If we are committed to making our relationship work, and making our relationship work, then we may produce something that is greater than the sum of its parts. Respect for one another is crucial, as is the ability to take the other's point of view. We are all 'idea carriers'. While I will not argue that all ideas have equal import, equal weight or equal value, they all deserve to be given voice. When we strive to answer such fundamental questions as how relationships are defined (or even more specialized questions such as how physical affection is defined), let us converse with colleagues from disciplines outside our own. If researchers are to view relationships from many different perspectives then we must not stick with only one method of observation. If we are striving for disciplinary integration, we must, in essence, learn to 'see' again (e.g. Lattuca, 1994).

One barrier that blinds us from 'seeing' through disciplinary boundaries might be the nature of standards for evaluation of our work. What 'works' in one discipline may not work in another. Or some disciplines may not even agree on the extent to which the question of 'what works' even matters. Thus, as disciplines differ in the extent to which they evaluate their work, some disciplines may devalue the work of the others. Maybe one reason the biological sciences are so readily interdisciplinary could be that the various disciplines within the biological fields (e.g. biochemistry, physiology) have the same criteria for evaluating their research. Thus, understanding the different evaluative standards and fostering respect for one another's work may be necessary first steps in crossing boundaries between disciplines.

As researchers from different disciplines, we see each other regularly at conferences, and some of us may have pleasant personal relationships with one another. It is time to have working relationships with researchers from disciplines other than our own. Let us graduate from parallel to interactive play. 


\section{NOTE}

The following five people from four different disciplines (biochemistry, communication, education, psychology) deserve thanks. All of them provided feedback on this manuscript and generously shared their ideas. My friend, colleague and collaborator, Elizabeth Douvan, also provided me with support and encouragement during the many phases of writing this manuscript. I thank her for continuing to teach me the meaning of collaboration. A primary source of inspiration for this manuscript was a letter from Leslie Baxter and subsequent conversations we had regarding the multidisciplinary nature of our field. My thanks also go to Lisa Lattuca, who generously provided me with several important ideas and resources, to James Smolen, who provided me with ideas about and examples of interdisciplinary work in biochemistry, and to Steve Duck, who shared several research ideas and provided me with the disciplinary affiliations of authors who were not in the INPR Directory. Preparation of this manuscript was supported, in part, by a grant from the National Institute of Mental Health (R01-MH46567).

\section{REFERENCES}

Acitelli, L.K. (1988) 'When Spouses Talk to Each Other about Their Relationship', Journal of Social and Personal Relationships 5(2): 185-99.

Acitelli, L.K. (1993) 'You, Me, and Us: Perspectives on Relationship Awareness', in S.W. Duck (ed.) Individuals in Relationships (Understanding Relationship Processes 1), pp. 14474. Newbury Park, CA: Sage.

Birnbaum, P.H. (1981) 'Academic Interdisciplinary Research: Characteristics of Successful Projects', Journal of the Society of Research Administrators 13(1): 5-16.

Diamond, A.M. (1992) 'Creativity and Interdisciplinarity: A Response to Rubenson and Runco', New Ideas in Psychology 10: 157-60.

Duck, S.W. (1990) 'Relationships as Unfinished Business: Out of the Frying Pan and into the 1990s', Journal of Social and Personal Relationships 7(1): 5-28.

Duck, S.W. (1994) Meaningful Relationships: Talking, Sense, and Relating. Thousand Oaks, CA: Sage.

Duck, S.W., Lock, A., McCall, G., Fitzpatrick, M.A. \& Coyne, J.C. (1984) 'Social and Personal Relationships: A Joint Editorial', Journal of Social and Personal Relationships 1(1): 1-10.

Epton, S.R., Payne, R.L. \& Pearson, A.W. (1983) Managing Interdisciplinary Research. Chichester: John Wiley.

Fish, S. (1994) There's No Such Thing as Free Speech, and It's a Good Thing, Too. New York: Oxford University Press.

Genero, N.P., Miller, J.B., Surrey, J. \& Baldwin, L.M. (1992) 'Measuring Perceived Mutuality in Close Relationships: Validation of the Mutual Psychological Development Questionnaire', Journal of Family Psychology 6(1): 36-48.

Good, J.M.M. \& Still, A.W. (1992) 'The Idea of an Interdisciplinary Social Psychology: An Historical and Rhetorical Analysis', Canadian Psychology 33: 563-8.

Kelley, H.H., Berscheid, E., Christenson, A., Harvey, J.H., Huston, T.L., Levinger, G., McClintock, E., Peplau, L.A. \& Peterson, D.R. (1983) Close Relationships. New York: W.H. Freeman.

Klein, J.T. (1990) Interdisciplinarity: History, Theory, and Practice. Detroit: Wayne State University Press.

Lattuca, L.R. (1994) 'Interdisciplinary Praxis: The Processes, Contexts, and Outcomes of Interdisciplinary Interaction Among College and University Faculty', Dissertation proposal, Center for the Study of Higher and Postsecondary Education, University of Michigan, Ann Arbor. 
Mayville, W.V. (1978) Interdisciplinarity: The Mutable Paradigm. Washington, DC: AAHEERIC/Higher Education Research Report No. 9.

Mitchell, P. \& Moyle, J. (1967) 'Chemiosmotic Hypothesis of Oxidative Phosphorylation', Nature 213: 137-9.

Parten, M.B. (1932) 'Social Participation Among Preschool Children', Journal of Abnormal and Social Psychology 27: 243-69.

Salsinger, K. (1994) 'The One with the Most Citations Wins', American Psychologist 49: 816.

Veroff, J., Sutherland, L., Chadiha, L. \& Ortega, R.M. (1993) 'Newlyweds Tell Their Stories: A Narrative Method for Assessing Marital Experiences', Journal of Social and Personal Relationships 10: 437-57. 